Mr. Neville Chamberlain's reply shows that he has given the most serious consideration to the questions involved, and that he is fully impressed with the dangers of allowing opticians untrained in medical matters to deal with defects of vision. It will be remembered that the Council of British Ophthalmologists issued a report on sight-testing by opticians (Brit. Jl. of Ophthal., Vol. VI, p. 554,1922$)$; and it is gratifying to note that the arguments and general tenor of the Minister's reply are in concord with the views expressed in that report.

\title{
"Optic Neuritis" and Cerebral Tumour
}

At a recent meeting of the Royal Medico-Chirurgical Society of Glasgow there was a discussion on this subject which was instituted, apparently, by $\mathrm{Mr}$. Archibald Young, Professor of Surgery at the University, with a view of obtaining information which would be of value in surgical work. He asked the ophthalmologists a number of questions such as "What the ophthalmologist really means by optic neuritis?" and "What are the features by means of which he recognizes one type of optic neuritis from another, if, indeed, he does so?" and so on. To most of the questions asked we are afraid that the answers given by the ophthalmologists-in this instance Drs. H. W. Thomson and A. J. Ballantyne-can be fairly well summed up in the wellknown Parliamentary reply: "the answer is in the negative." The discussion of the subject was very interesting and revealed a large amount of work and thought on the part of the speakers; it will well repay perusal in the Glasgow Medical Journal of January, 1926. But we fear that the surgeon will not find much help in the conclusion that "in so far as one can be satisfied that oedematous swelling of the optic disc predominates over the retinal changes, one is justified in suspecting intracranial increase of pressure as the cause rather than a toxaemia or vascular sclerosis. In no case is it possible to assess the ocular condition until examination of the patient has revealed the presence or absence of the possible causes to which reference has already been made." Yet we do not think the ophthalmologist is at the present time in a position to make the statement any firmer than this pronouncement by $\mathrm{Dr}$. H. W. Thomson.

The following excerpt from Dr. Ballantyne's remarks is worthy of reproduction. It is as follows: "these two problems-that of the relief of the papilloedema and other pressure symptoms, and that of the removal of the neoplasm-are sometimes allowed to be confused with each other. They are two entirely different matters, and, as an oculist, I would like to make a plea for greater concentration on the simpler problem of decompression for the preservation of sight. No doubt it is a higher aim to attempt the 
localization and removal of the tumour, but there must be some limit to the time allowed for clinical observation, and experience shows that the number of cases in which the growth is not only localizable but operable is very small. The real benefits of decompression are available for a much larger proportion of the cases, and if this procedure is delayed in the hope of receiving greater benefit, disappointment will be the rule rather than the exception, and the moment favourable for decompression will pass." With these words we think a large proportion of our readers will agree. Further, they constitute at least some sort of reply to the questions asked by the surgeon.

\section{Ophthalmic Benefit}

From some questions which were recently asked in the House of Commons, a brief report of which appeared in the British Medical Journal of March 6, 1926, it appears that some panel practitioners refer a much higher proportion of their cases for ophthalmic treatment than do others. Any ophthalmic surgeon to a general hospital serving a London district could have told the authorities that this would be the case. The questioner seemed to think that more uniformity could be obtained by orders from headquarters; so it could, but it would be most unjust to attempt anything of the sort. It would be manifestly unfair to limit the number of cases on a panel that the practitioner couid refer for ophthalmic benefit. Suppose for a moment that a panel of 1,000 were allowed only 5 per cent. of the whole to be sent for ophthalmic treatment in any one year, and that the fifty-first applicant was suffering from some serious eye disease; the latter would, it seems to us, have a good case in law against the limiting body, if he or she had to wait a year or even a week for advice and treatment. Flagitio additis damnum.

One way in which to obtain more uniformity would be to require the ophthalmic surgeon when giving his prescription, or when submitting his account to the approved societies, to furnish a certificate that of the cases seen so many were legitimate cases to have been sent for ophthalmic benefit, and so many were not; but this would lead to endless trouble, as some people take a much broader outlook than others. The enthusiast who considers that every headache is ocular in origin and who sees in the correction of a small amount of astigmatism a cure for conditions ranging from dyspepsia to miners' nystagmus is perfectly at liberty to have his own opinions and to send every patient on his panel for ophthalmic benefit ; while the approved societies could hardly take it upon themselves to refuse benefit, as no one could take an affidavit to the effect that the wearing of glasses might not possibly improve a patient's general health and so lead to an improvement 